\title{
INFLUENCE OF SUPPLEMENTING SPERM MEDIUM WITH TYPE-13 BRAZILIAN RED PROPOLIS EXTRACT ON CHILLED RAM SEMEN PRESERVATION
}

\author{
I.S. Abd El-Hamid ${ }^{1}$, M.A. Khalifa ${ }^{1}$, S.A. Rateb ${ }^{1}$, A.S. Morsy ${ }^{2}$, M.T. Badawy ${ }^{1}$ and H.A. Gawish ${ }^{1}$ \\ 1- Animal and Poultry Production Division, Desert Research Center, Ministry of Agriculture and Land \\ Reclamation, Egypt, 2- Livestock Research Department, Arid Land Cultivation Research Institute, City of \\ Scientific Research and Technological Applications, Alexandria, Egypt
}

Received: 11/11/2018

Accepted: 3/1/2019

\section{SUMMARY}

Two experiments were carried out to evaluate the dual purpose potential of type-13 Brazilian red propolis extract; i.e. anti-oxidant and anti-microbial capacities, on enhancing short-term chilled preservation of ram semen. A total of 60 ejaculates were collected from five adult Barki rams, 12 ejaculates each, by an artificial vagina twice-weekly during the period from January to February, 2017. After collection and initial evaluation, ejaculates of each collection session were pooled, diluted (1:10) with Tris-citric acid egg yolk extender. In the first experiment, the diluted specimens were split into four aliquots using a split sample technique. The first aliquot served as control (untreated), whereas the other three aliquots were supplemented with 5, 7.5 and 10 $\mu \mathrm{l} / \mathrm{mL}$ propolis extract, respectively. All control and supplemented groups were evaluated for sperm physical and morphological traits immediately after dilution $\left(T_{0}\right)$, then after $24\left(T_{24}\right)$ and $48 h\left(T_{48}\right)$ of chilled preservation at $4^{\circ} \mathrm{C}$. Oxidative stress indices and enzymatic activities in medium throughout preservation period were also determined. In the second trial, microbial contamination throughout a $48 \mathrm{~h}$ period of chilled storage was investigated in specimens supplemented with the same previous levels of propolis extract and were compared against control (antibiotic-free) and specimens supplemented with a mixture of synthetic antibiotics; i.e. Penicillin procaine $(500 \mathrm{iu} / \mathrm{mL})$ and Streptomycin $(500 \mu \mathrm{g} / \mathrm{mL})$. The results revealed that, over time of storage, positive correlations $(P<0.05)$ were observed between level of propolis in medium and each of sperm motility, viability, intact acrosome, sperm membrane integrity and total antioxidant capacity $(r=0.52,0.45$, $0.48,0.55$ and 0.77 , respectively). Contrarily, negative correlations were recorded between propolis level and enzymatic activities of AST and ALP ( $r=-0.45$ and -0.58 , respectively). Simultaneously, the control group developed the highest $(P<0.05)$ colony forming unit $(C F U)$ count compared to all semen specimens. These results explicate efficiency of incorporating type-13 Brazilian red propolis extract in the diluent on maintaining sperm traits during chilled preservation. Additionally, our results spotted the light on the possibility of substituting synthetic antibiotics in semen extenders, with all the constraints of their utilization, with type-13 red propolis extract as a sufficient natural alternative.

\section{Keywords: Propolis, Semen diluent, Ram, Antibiotics, CFU, AI}

\section{INTRODUCTION}

Propolis is natural resinous products which is collected by honeybees from several plants and mix it with beeswax and $\beta_{-}$glucosidase (salivary enzymes) (Cardoso et al., 2011). Propolis possesses a unique chemical composition that comprises complexity of compounds; i.e. polyphenols, which makes it a potent antioxidant (Scalbert et al., 2005; Almaraz-Abarca et al., 2007 and Nader et al., 2010). Moreover, it exhibits major effects against several bacterial strains and fungi as well as antiviral activity (Scazzocchio et al., 2006). Therefore, propolis has been used by humans to benefit from its broad spectrum of biological properties particularly of clinical interest (Fokt et al., 2010).

Generally, liquid-chilled preservation of semen has been reported to reduce the fertilizing capacity of spermatozoa along with both sperm motility and morphology over time of storage (Munsi et al., 2007). Accumulation of reactive oxygen species (ROS) in medium during liquid storage of semen initiates oxidative reactions that eventually lead to the death of the sperm cells (Guerra et al., 2004). Therefore, application of antioxidants to semen diluents gained considerable attention in assisted reproductive technology (ART's) practices (Hashem et al., 2017).

On the other side, microbial contamination of either fresh or preserved semen represents another constrain in application of ART's, and may paradoxically contributes in wide spread of pathogens (Foote, 2002). In addition, microbial contamination of semen may lead to rapid decline in sperm motility and subsequent fertility (Shukla, 2005 and Morrell, 2006).

Using antimicrobials in semen diluent may have detrimental effects on sperm survival, motility, vitality and subsequent fertility due to their toxic effects (Shukla, 2005; Morrell, 2006 and Aurich and Spergser, 2007). Therefore, a cocktail of agents has been commonly used in semen extenders to reduce the effect of each individual component. However, the choice of agents that can be added to semen 
extenders is limited. In well-developed countries, addition of antibiotics to semen diluents is stipulated by national and international guidelines. Nevertheless, although many countries are trying to reduce the general use of antibiotics, the addition of antibiotics to semen extenders increases (Morrell and Wallgren, 2014). In this regard, finding natural alternative agents to antibiotics will be useful to improve sperm quality during preservation.

Therefore, the present study aimed to investigate the effect of supplementing semen diluent with type13 Brazilian red propolis extract on maintaining ram sperm traits during $48 \mathrm{~h}$ of chilled preservation at $4^{\circ} \mathrm{C}$. The antimicrobial potential of propolis extract throughout the period of chilled storage was also determined.

\section{MATERIALS AND METHODS}

\section{Animals and management}

The current study was conducted at the Artificial Insemination Lab., Mariout Research Station (Latitude $31^{\circ} 00^{\prime} \mathrm{N}$; Longitude $29^{\circ} 47^{\prime} \mathrm{E}$ ), Desert Research Center, Egypt. Five adult Barki rams, Ovis aries, aged 28-40 months and an average body weight of $45.0 \pm 2.0 \mathrm{~kg}$ were used from January to
February, 2017. Throughout the experimental period, the rams were housed in a fenced open yard. They were allowed to graze daily from 8:00 to 14:00 h, thereafter Egyptian clover, Trifolium alexandrinum, hay was provided ad libitum, and a concentrate mixture was presented to meet their requirements (NRC, 2007). Fresh water was available once daily after returning from the pasture. Prior to executing the experiment, all rams were clinically examined to be sure that they were free of disease or reproductive disorders. The experimental procedures were conducted in conformity with the European Union Directive for the protection of experimental animals (2010/63/EU).

\section{Propolis extraction, purification and chemical composition determination}

A modified technique for type-13 Brazilian red propolis extraction was used as described by Morsy et al. (2013). The chemical composition of the purified propolis extract was determined by gas chromatography-mass spectrometry (Morsy et al., 2013 and Morsy et al., 2015). The identification and quantitative measurements of type-13 Brazilian red propolis extract constituents are presented in figure 1 .

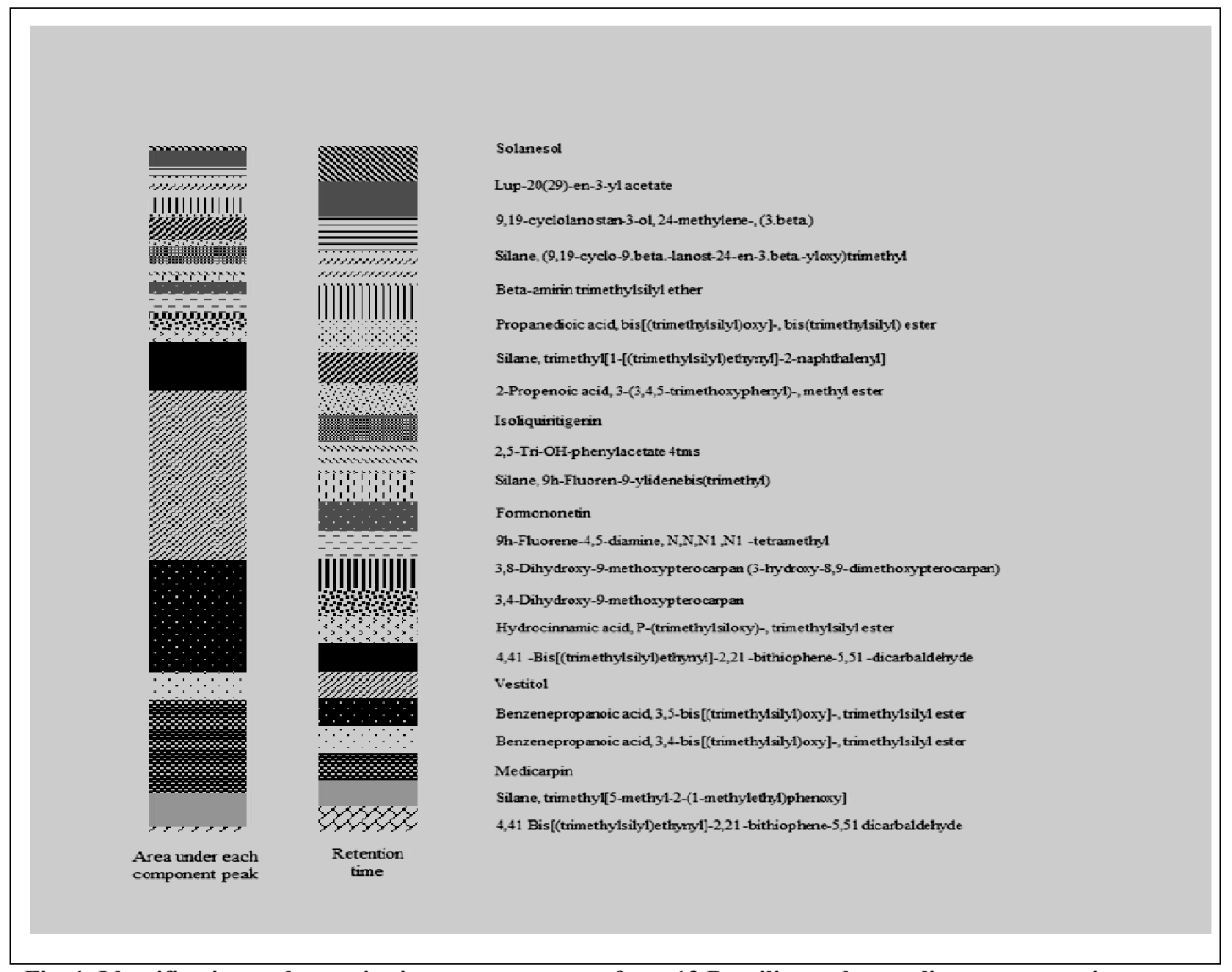

Fig. 1. Identification and quantitative measurements of type13 Brazilian red propolis extract constituents as determined by gas chromatography-mass spectrometry 


\section{Semen diluents:}

All chemicals used in the present experiment were obtained from Sigma (Sigma-Aldrich). A triscitric egg yolk extender was prepared for dilution of ram semen by slightly modifying the extender reported by Kulaksiz et al. (2012). The extender was composed of tris buffer $(0.25 \mathrm{Mol}, 3.63 \%)$, citric acid $(1.99 \%)$, glucose $(0.5 \%)$, and was further supplemented with egg-yolk (40 \%). Immediately after preparation the diluents was centrifuged at $2400 \mathrm{~g}$ for $15 \mathrm{~min}$, and the clarified supernatant was aspirated. The extender was prepared $24 \mathrm{~h}$ prior to each collection session and was stored at $4{ }^{\circ} \mathrm{C}$ until used.

\section{Semen collection:}

A total of 60 ejaculates were collected from the rams, 12 ejaculates each, throughout the two months of the study period. Collection of semen was performed at 7 a.m. twice weekly by an artificial vagina as previously described (ElBahrawy et al., 2004).

\section{Semen evaluation and experimental design:}

Immediately after collection, raw semen samples were transported to the laboratory, and ejaculate volume $(\mathrm{mL})$ was recorded using the graded collection tube. In addition, $\mathrm{pH}$, mass motility, and sperm concentration were recorded for each raw ejaculate. The mean values of the aforementioned criteria throughout the experimental period were $0.99 \pm 0.04 \mathrm{~mL}, 6.85$ $\pm 0.08, \quad 4.47 \pm 0.07$ and $2340.21 \pm 15.29 \times 10^{6}$ sperm $/ \mathrm{mL}$, respectively. Thereafter, all good quality specimens (4-5 mass motility score; David et al., 2015) were pooled and were further diluted (1:10) with Tris-citric egg yolk extender.

Two experiments were carried out in the present study to evaluate the dual purpose potential of type13 Brazilian red propolis extract; i.e. anti-oxidant and anti-microbial capacities, on enhancing shortterm chilled preservation of ram semen. In the first experiment, the diluted specimens were split into 4 aliquots using a split sample technique. The first aliquot served as control (untreated), whereas the other 3 aliquots were supplemented with 5, 7.5 and $10 \mu 1 / \mathrm{mL}$ propolis extract, respectively. All diluted semen specimens were evaluated for sperm physical and morphometric characteristics immediately after dilution $\left(\mathrm{T}_{0}\right)$ then after $24\left(\mathrm{~T}_{24}\right)$ and $48 \mathrm{~h}\left(\mathrm{~T}_{48}\right)$ of preservation at $4{ }^{\circ} \mathrm{C}$.

\section{Semen assessment:}

Total sperm motility was assessed using a phase-contrast microscope (Leica) at $400 \mathrm{x}$ magnification, while sperm vitality (live and dead sperm, \%) were examined by the differential staining technique where a mixture of $10 \mu \mathrm{l}$ of semen and $5 \mu \mathrm{l}$ of freshly-prepared eosin-nigrosin stain was smeared on a warm stage, and were examined at $1000 \mathrm{x}$ magnification. Sperm abnormalities and acrosome integrity were evaluated using Romanowski's triplestain technique (DIFF-QUICK III, Vertex, Egypt). Smears preparation and staining procedure were conducted following instructions provided by the manufacturer, and the stained smears were evaluated using a phase-contrast microscope at 1000x magnification. Sperm plasma membrane integrity was determined by the hypo-osmotic swelling test (HOST) as described by Mosaferi et al. (2005), where at least 200 sperm were evaluated at $400 \mathrm{X}$ magnification.

Determination of antioxidant capacity and enzymatic activities in medium:

A $2 \mathrm{~mL}$ portion of each semen group was obtained and centrifuged (1000 g for $10 \mathrm{~min})$ at times parallel to those of semen assessment $\left(T_{0}, T_{24}\right.$ and $\mathrm{T}_{48}$ ). The supernatant was collected and stored at $-20{ }^{\circ} \mathrm{C}$ until oxidative stress indices and enzymatic activities were analyzed. Total antioxidant capacity (TAC) was analyzed using colorimetric kits (Biodiagnostic, Egypt). The changes in alanine aminotransferase (ALT) and aspartate aminotransferase (AST) concentrations were analyzed by colorimetric kits (Spectrum, Egypt). Activity of alkaline phosphatase (ALP) was determined colorimetrically using kits obtained from Biodiagnostic, Egypt. All procedures were conducted according to the manufacturers' instructions.

\section{Determination of microbial load:}

In the second experiment, microbial contamination throughout a $48 \mathrm{~h}$ period of chilled storage was investigated in specimens supplemented with the same previous levels of propolis extract and were compared against control (antibiotic-free) and synthetic antibioticssupplemented groups. The diluent of the latter group was supplemented with a mixture of Penicillin procaine $(500 \mathrm{iu} / \mathrm{mL})$ and Streptomycin $(500 \mu \mathrm{g} / \mathrm{mL})$ before being preserved at $4{ }^{\circ} \mathrm{C}$ as previously described. Within $15 \mathrm{~min}$ after the periodic evaluation of semen characteristics $\left(\mathrm{T}_{0}\right.$, $\mathrm{T}_{24}, \mathrm{~T}_{48}$, a sample of each chilled specimen was transported, in a portable cooling cabinet $\left(5^{\circ} \mathrm{C}\right)$, to a well-equipped medical lab. The specimens were subjected to automated determination of colony forming unit (CFU) and microbial identification using the VITEK $^{\circledR} 2$ system $\left(\right.$ VITEK $^{\circledR} 2$, BioMérieux, USA). The determination procedure was conducted according to the manufacturer's instruction.

\section{Statistical analysis:}

The data were arcsine transformed to improve the approximation of normality. Mean values of raw semen characteristics were obtained by simple student's t-test. The changes in sperm physical and morphological traits, as well as oxidative indices and enzymatic activities, throughout the period of chilled preservation were statistically analyzed by 
repeated measures analysis of variance (ANOVA) to determine the fixed effects of level of treatment, time $\left(\mathrm{T}_{0}-\mathrm{T} 4_{8}\right)$ and treatment by time interaction according to the following model:

$Y_{i j}=\mu+A_{i}+B_{j}+A_{i j}+e_{i j k}$

Where, $Y_{i j}$ is the value of treatment (i) measured at a time $(\mathrm{j}) ; \mu$ is the overall mean; $\left(\mathrm{A}_{\mathrm{i}}\right)$ is a fixed effect describing variation among levels of treatment; $\left(B_{j}\right)$ is a fixed effect describing variation among times of observation; $\left(\mathrm{AB}_{\mathrm{ij}}\right)$ describes the interaction between levels of treatment and time of observation; and $\left(\mathrm{e}_{\mathrm{ijk}}\right)$ is the residual variation.

A similar procedure and statistical model was used to determine the changes in developing colony forming unit among control and treated specimens over time of storage. The differences between means were detected by Duncan's post-hoc test. The correlations between level of propolis in medium and both sperm traits and enzymatic activities were obtained by rank correlation coefficient. Significance was set at 5\% and data were analyzed by IBM-SPSS statistics program (IBM-SPSS, 2013). The results are expressed as means \pm standard error (SEM).

\section{RESULTS AND DISCUSSION}

\section{Effects on chilled semen traits}

The results showed that mean values of sperm motility drastically declined $(\mathrm{P}<0.05)$ over time of preservation in control specimens compared to all propolis-supplemented groups, recording the lowest $(\mathrm{P}<0.05)$ values at $\mathrm{T}_{48}$ (Fig. 2). A similar trend was also observed in sperm viability, where all propolis-supplemented specimens recorded higher $(\mathrm{P}<0.05)$ values of live sperm percent at 48 $\mathrm{h}$ of chilled storage compared to control (Fig. 2). In the meantime, the percent of normal sperm in the control group was affected $(\mathrm{P}<0.05)$ by time of storage, recording the lowest $(\mathrm{P}<0.05)$ values at $\mathrm{T}_{48}$ compared to all treated specimens (Fig. 2). Contrariwise, the highest $(\mathrm{P}<0.05)$ percent of secondary sperm abnormalities was observed in the control group compared to propolis-supplemented specimens at $\mathrm{T}_{48}$ (Fig. 2). Regarding sperm acrosomal status and membrane stability, the results illustrated that both criteria declined $(\mathrm{P}<0.05)$ over time of preservation in the control group compared to all other specimens, and recorded the lowest $(\mathrm{P}<0.05)$ values at $\mathrm{T}_{48}$ (Fig. 2$)$.

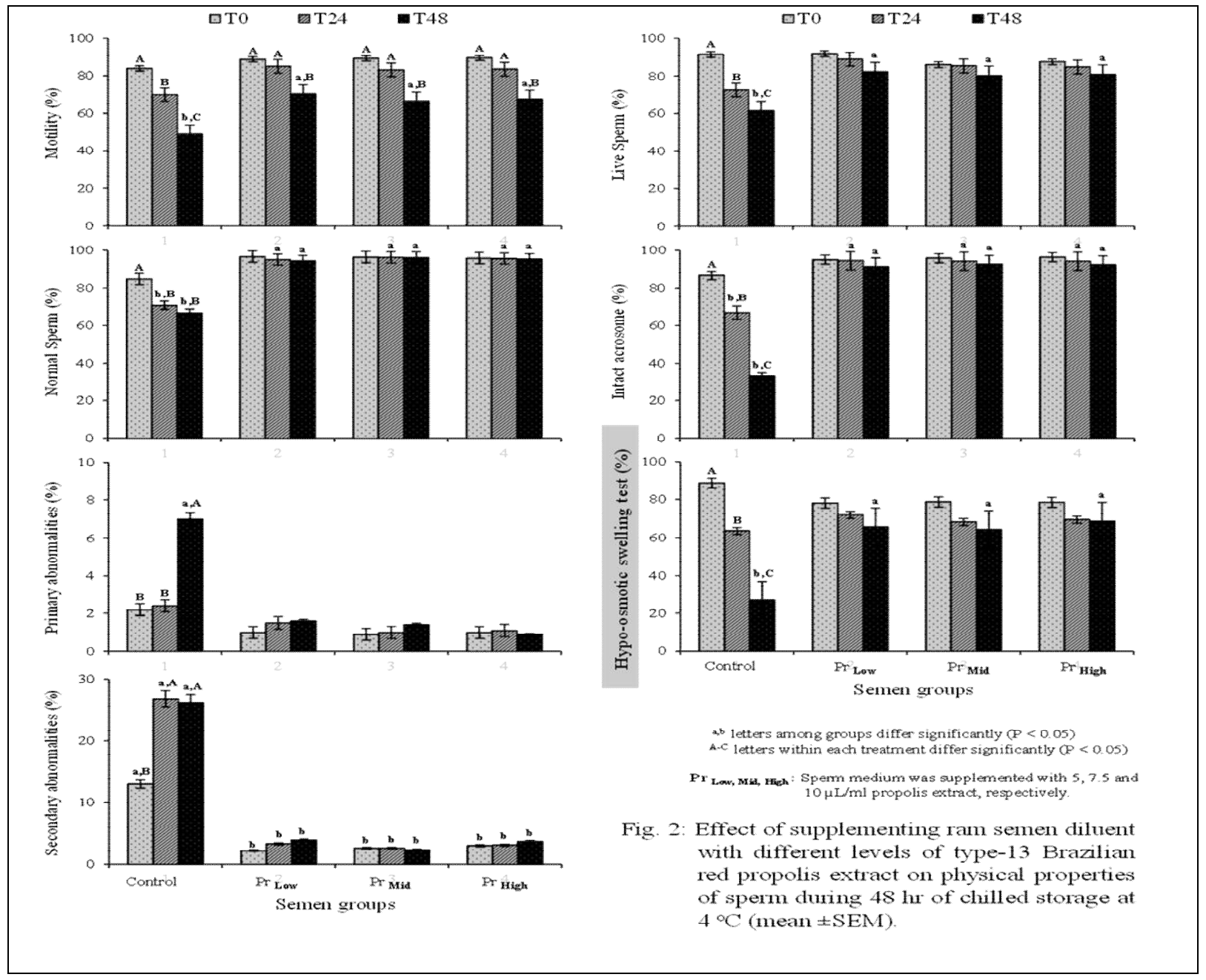

The fertilizing capacity of chilled-preserved spermatozoa has been reported to decrease over time of storage along with both sperm motility and morphology (Munsi et al., 2007), since cooled storage exposes spermatozoa to the drastic effects of spontaneous lipid peroxidation (Foote et al., 2002; 
Agarwal et al., 2003). The increased LPO reaction in addition to capacitation and hyperactivation of spermatozoa over time of cooled preservation increase production of free radicals (Mathur and D'Cruz, 2011). Overproduction and accumulation of ROS in preservation medium has been reported to impair sperm integrity (Paul et al., 2009) and eventually lead to the death of the sperm cells (Guerra et al., 2004).

\section{Effects on oxidative status during preservation}

The results also showed a severe decline $(\mathrm{P}<0.05)$ in total antioxidant capacity (TAC) level in sperm medium of control specimens over storage period (Table 1). At $\mathrm{T}_{48}$, the highest $(\mathrm{P}<0.05)$ values of TAC in the diluent was observed in specimens supplemented with high propolis level, whereas the lowest $(\mathrm{P}<0.05)$ was recorded in the control group with values $0.83 \pm 0.08$ and $0.35 \pm 0.03 \mathrm{mM} / \mathrm{L}$, respectively. On the other hand, neither time of storage nor sperm groups were significantly affected level of ALT in medium (Table 1). However, the highest $(\mathrm{P}<0.05)$ level of AST was recorded in medium of control group at $\mathrm{T}_{48}$, while the lowest level $(\mathrm{P}<0.05)$ was observed in the high-propolis level group (Table 1). Likewise, levels of ALP followed the same trend with corresponding values $255.6 \pm 8.9$ and $168.4 \pm 13.3 \mathrm{U} / \mathrm{L}$, respectively (Table 1). Malondialdehyde (MDA) is commonly analyzed to measure peroxidative damage in spermatozoa since it is a byproduct of lipid peroxidation (Makker et al., 2009). Furthermore, the increased activities of both AST and ALT in medium directly indicate sperm membrane damage (Pesch et al., 2006), and reflect increased percentages of dead and abnormal spermatozoa (Gundogan et al., 2010). Likewise, a high positive correlation has been reported between ALP activity released by spermatozoa and semen quality when sperm cells were subjected to sever stress (Ciereszko et al., 1992).

Table 1. Effect of supplementing ram semen medium with type-13 Brazilian red propolis extract on total antioxidant capacity and enzymatic activities during $48 \mathrm{~h}$ of chilled storage at $4^{\circ} \mathrm{C}$ (Mean \pm SEM).

\begin{tabular}{|c|c|c|c|c|c|}
\hline \multirow{2}{*}{ Parameter } & \multirow{2}{*}{$\begin{array}{l}\text { Time of preservation } \\
\text { (hrs) }\end{array}$} & \multirow[b]{2}{*}{ Control } & \multicolumn{3}{|c|}{ Level of propolis extract } \\
\hline & & & $\begin{array}{c}\text { Low } \\
(5 \mu \mathrm{L} / \mathrm{ml})\end{array}$ & $\begin{array}{l}\text { Medium } \\
(7.5 \mu \mathrm{L} / \mathrm{ml})\end{array}$ & $\begin{array}{c}\text { High } \\
(10 \mu \mathrm{L} / \mathrm{ml})\end{array}$ \\
\hline \multirow{3}{*}{$\begin{array}{l}\text { TAC } \\
(\mathbf{m M} / \mathbf{L})\end{array}$} & $\mathrm{T}_{0}$ & $0.65 \pm 0.06^{\mathrm{A}}$ & $0.62 \pm 0.06$ & $0.82 \pm 0.09$ & $0.92 \pm 0.08$ \\
\hline & $\mathrm{T}_{24}$ & $0.36 \pm 0.02^{\mathrm{b}, \mathrm{B}}$ & $0.54 \pm 0.02^{b}$ & $0.49 \pm 0.07^{\mathrm{b}}$ & $0.84 \pm 0.06^{\mathrm{a}}$ \\
\hline & $\mathrm{T}_{48}$ & $0.35 \pm 0.03^{\mathrm{b}, \mathrm{B}}$ & $0.51 \pm 0.05^{b}$ & $0.41 \pm 0.03^{b}$ & $0.83 \pm 0.08^{\mathrm{a}}$ \\
\hline \multirow{3}{*}{$\operatorname{ALT}(\mathbf{U} / \mathbf{L})$} & $\mathrm{T}_{0}$ & $95.97 \pm 3.9$ & $96.45 \pm 2.2$ & $102.49 \pm 2.6$ & $103.29 \pm 0.7$ \\
\hline & $\mathrm{T}_{24}$ & $104.23 \pm 2.4$ & $105.35 \pm 1.0$ & $105.58 \pm 0.9$ & $101.37 \pm 1.5$ \\
\hline & $\mathrm{T}_{48}$ & $102.02 \pm 5.2$ & $102.03 \pm 5.2$ & $91.32 \pm 2.5$ & $99.00 \pm 2.3$ \\
\hline \multirow{3}{*}{$\operatorname{AST}(\mathbf{U} / \mathbf{L})$} & $\mathrm{T}_{0}$ & $213.34 \pm 5.6^{\mathrm{B}}$ & $223.55 \pm 10.3$ & $216.57 \pm 9.7$ & $233.15 \pm 5.7$ \\
\hline & $\mathrm{T}_{24}$ & $240.99 \pm 5.9^{\mathrm{B}}$ & $240.89 \pm 3.5$ & $233.59 \pm 10.5$ & $237.63 \pm 7.5$ \\
\hline & $\mathrm{T}_{48}$ & $247.60 \pm 3.8^{\text {a, A }}$ & $242.39 \pm 2.0^{\mathrm{ab}}$ & $247.59 \pm 4.5^{\mathrm{a}}$ & $235.26 \pm 4.1^{\mathrm{b}}$ \\
\hline \multirow{3}{*}{$\operatorname{ALP}(\mathbf{U} / \mathbf{L})$} & $\mathrm{T}_{0}$ & $253.11 \pm 5.3^{\mathrm{a}}$ & $161.46 \pm 3.9^{\mathrm{b}, \mathrm{B}}$ & $217.37 \pm 12.3^{\mathrm{ab}, \mathrm{B}}$ & $233.46 \pm 6.3^{\mathrm{a}}$ \\
\hline & $\mathrm{T}_{24}$ & $248.25 \pm 3.8$ & $252.79 \pm 5.0^{, \mathrm{A}}$ & $242.44 \pm 3.1^{\mathrm{AB}}$ & $233.38 \pm 11.9$ \\
\hline & $\mathrm{T}_{48}$ & $255.59 \pm 8.9^{\mathrm{a}}$ & $255.85 \pm 4.9^{\mathrm{a}, \mathrm{A}}$ & $257.93 \pm 3.5^{\text {a, A }}$ & $168.35 \pm 13.3^{b}$ \\
\hline
\end{tabular}

\section{Effects on microbial contamination during preservation}

Initial results of microbial contamination showed that type of supplementation in sperm medium affected $(\mathrm{P}<0.05)$ total colony forming unit $(\mathrm{CFU})$ count over time of preservation in all semen groups. The highest $(\mathrm{P}<0.05)$ CFU count was recorded in both control (untreated) and low-propolis level groups, over time of storage, compared to all semen specimens (Fig. 3). Microbial contamination of semen also leads to rapid decline in sperm motility (Shukla, 2005; Morrell, 2006) and sperm quality, either by directly competing with spermatozoa for nutrients supplied by the extender or by the production of toxic metabolic byproducts and endotoxins (Morrell and Wallgren, 2014).

Collectively, the results of the current study showed that inclusion of type-13 Brazilian red propolis extract in ram sperm medium improved $(\mathrm{P}<0.05)$ sperm physical properties and reduced level of microbial contamination over a $48 \mathrm{~h}$ period of chilled storage. This was clearly evident since a positive correlation $(\mathrm{P}<0.05)$ was observed between level of propolis in medium and each of sperm motility, live sperm, intact acrosome, sperm membrane integrity and total antioxidant capacity $(\mathrm{r}=$ $0.52,0.45,0.48,0.55$ and 0.77 , respectively) over time of storage. Contrarily, a negative correlation was recorded between propolis level and enzymatic activities of AST and ALP $(r=-0.45$ and -0.58 , 
respectively).

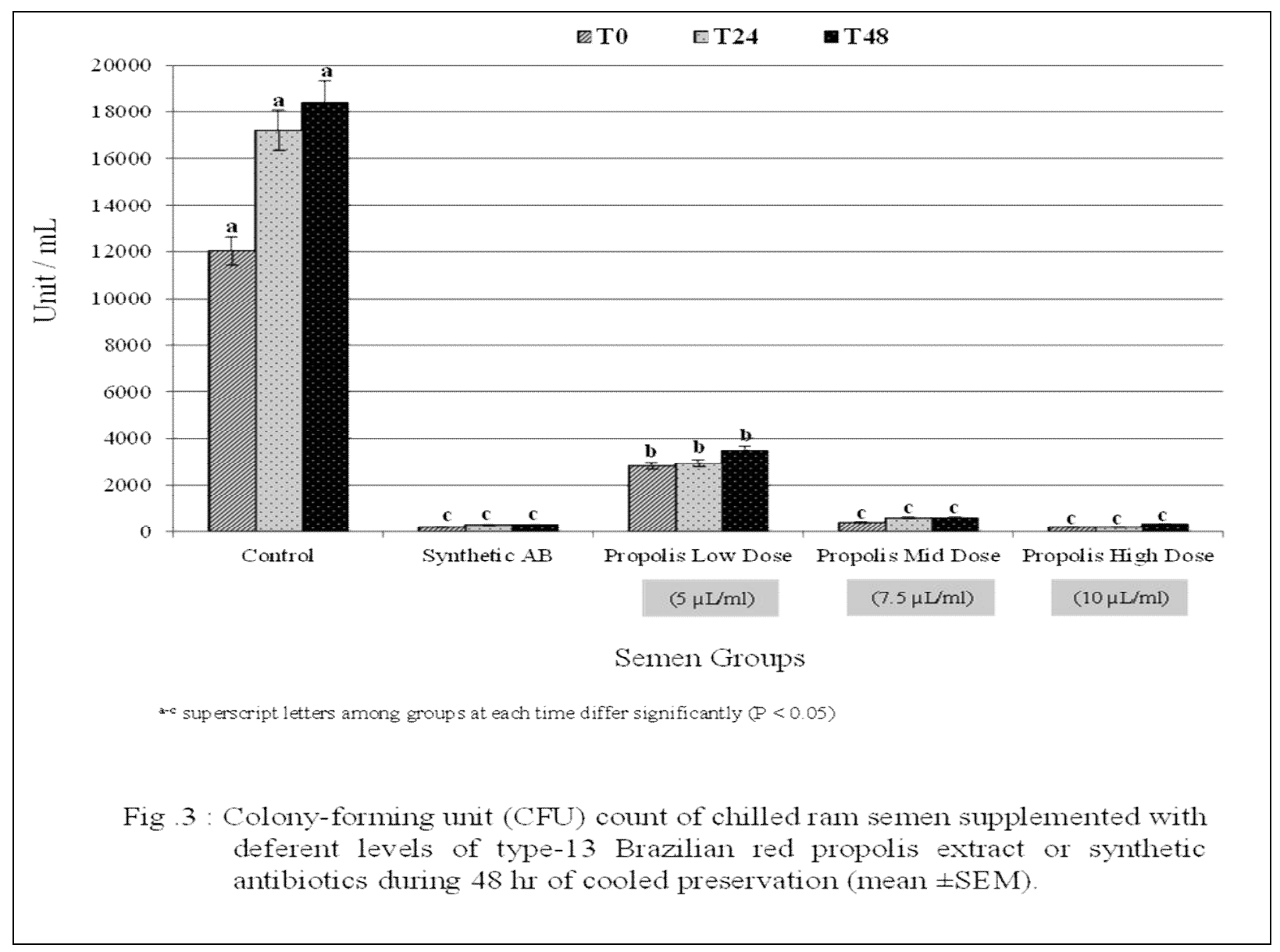

Propolis is a natural resinous substance that contains more than 300 identified phenolic compounds belonging to three major groups; i.e. flavonoids, phenolic acids and esters (Simoes et al., 2004). These components are responsible for propolis antioxidant, antimicrobial, anti-parasitic, antiviral and anti-inflammatory properties (Kumazawa et al., 2004; Paulino et al., 2008). The GC-MS spectrophotometry analysis of type-13 Brazilian red propolis extract conducted in the current investigation revealed that the extract contained high concentrations of flavones, flavonoids and long chain fatty acids. The isoflavonoid vestitol represented the major constituent of the extract $(24.6 \%)$ followed by both benzenepropanoic acid, 3,5bis[(trimethylsilyl)oxy]-, trimethylsilyl; i.e. hydrocinnamic acid (16.5\%) and medicarpin (13.5\%). Recently, vestitol isolated from Brazilian red propolis methanolic extract has been reported to exhibit in vivo anti-inflammatory and in vitro antimicrobial properties (Bueno-Silva et al., 2013; Franchin et al., 2016). Meanwhile, the phenylprobanoid, hydrocinnamic acid, has been utilized in food industry as an antioxidant and antimicrobial additive to prolong shelf life of foods (Korneev, 2013). Further, the pterocarpan, medicarpin, is an isoflavonoid derivative that belongs to the phytoalexins group (Hargreaves et al., 1976) and is considered a powerful antifungal compound
(Martínez-Sotres et al., 2012).

Along with other antioxidant bioactive agents that comprise Brazilian red propolis extract, the aforementioned components are capable of scavenging free radicals thereby providing protection against lipid peroxidation (Paulino et al., 2008; Yousef and Salama, 2009). Propolis has been also reported to induce activation of antioxidant enzymes; such as superoxide dismutase and catalase, against free radicals (Jasprica et al., 2007). This could explain the enhancement in sperm motility, vitality and membrane integrity in propolis-supplemented specimens compared to control over time of chilled preservation.

\section{CONCLUSIONS}

It can be inferred from the current results that supplementing ram semen extender with type-13 Brazilian propolis extract sufficiently mitigated the deleterious effects of chilled preservation and, thus, enhanced preservation capacity of ram spermatozoa. The results also spotted the light on the possibility of substituting synthetic antibiotics in semen extender with type-13 red propolis extract as natural alternative antibiotic.

\section{ACKNOWLEDGEMENT}


The authors are greatly indebted to Prof. Sobhy M. Sallam and to Dr. Yosra A. Soltan (Faculty of Agriculture, Alexandria University) for providing the Brazilian red propolis extract; and to each of Prof. S.M. Alencar and Prof. A.L. Abdalla (Universidade de São Paulo, Piracicaba, São Paulo, Brazila) for providing all the facilities and conducting extraction, identification and quantitative measurements of the extract. Gratitude is also extended to Prof. Dr. Mahmoud E. Al-Dequen and all the staff of AlAndalos Medical Lab. for providing all the facilities to perform the microbial contamination analysis.

\section{CONFLICT OF INTEREST}

The authors have no conflict of interest.

\section{REFERENCES}

Agarwal A., A. Ramadan and A.B. Mohamed, 2003. Role of reactive oxygen species in the pathophysiology of human reproduction. Fert. Steril, (79): 829-843.

Almaraz-Abarca N., C. M. da Graça., J.A. ÁvilaReyes., N. Naranjo-Jiménez., J. Herrera Corral and L.S. González-Valdez, 2007. Antioxidant activity of polyphenolic extract of monofloral honeybee-collected pollen from mesquite (Prosopis juliflora, Leguminosae). J. Food. Comp Anal, (20): 119-124.

Aurich C and J. Spergser, 2007. Influence of bacteria and gentamicin on cooled-stored stallion spermatozoa. Theriogenology, (67): 912-918.

Baldssarre H and C.N. Karatzas, 2004. Advanced assisted reproduction technologies (ART) in goats. Anim. Reprod. Sci, (82): 255 - 266.

Bueno-Silva B., S.M. Alencar., H. Koo. M. Ikegaki., G.V. Silva., M.H. Napimoga and P.L. Rosalen, 2013. Anti-inflammatory and antimicrobial evaluation of neovestitol and vestitol isolated from Brazilian red propolis. J. Agric. Food Chem, (61): 4546-4550.

Cardoso S.M., M. Ribeiro, I.L. Ferreira and C.A. Rego, 2011. Northeast Portuguese propolis protects against staurosporine and hydrogen peroxide-induced neurotoxicity in primary cortical neurons. Food Chem. Toxicol, (49): 2862-2868.

Ciereszko A., J. Glogowski., J. Strzezek and W. Demianowicz, 1992. Low stability of aspartate aminotransferase activity in boar's semen. Theriogenology, (37): 1269-1281.

David I., P. Kohnke., G. Lagriffoul., O. Praud., F. Plouarboué., P. Degond and X. Druart, 2015. Mass sperm motility is associated with fertility in sheep. Anim. Reprod. Sci, (161): 75-81.

El-Bahrawy K.A., E.E. El-Hassanein., A.Z. Fathelbab., M.M. Zeitoun and A.M. Yaseen, 2004. Desert climatic effects on freezability and some biochemical constituents of Barki ram semen. Mansoura J. Agric. Sci, (29): 3123-3132.

Fokt H., A. Pereira., A.M. Ferreira., A. Cunha and C. Aguiar, 2010. How do bees prevent hive infections? The antimicrobial properties of propolis. In: Current Research, Technology and Education Topics in Applied Microbiology and Microbial Biotechnology, A. Mendez-Vilas, Ed., vol. 1 of Microbiology Book Series-Number 2, pp. 481-493.

Foote R.H., 2002. The history of artificial insemination: Selected notes and notables. J. Anim. Sci, (80): 1-10.

Foote R.H., C.C. Brochkett and M.T. Kaproth, 2002. Motility and fertilizing of bull sperm in whole milk extender containing antioxidants. Anim. Reprod. Sci, (71): 13-23.

Franchin M., D.F. Cólon., F.V. Castanheira., M.G. da Cunha., B. Bueno-Silva., S.M. Alencar., T.M. Cunha and P.L. Rosalen, 2016. Vestitol isolated from Brazilian red propolis inhibits neutrophils migration in the inflammatory process: Elucidation of the mechanism of action. J. Nat. Prod, (79): 954-60.

Guerra M. M. P., G. Evans and W. M. C. Maxwell, 2004. The role of oxidants and antioxidants on andrology. Revista Brasileira De Reprodução. Animal, (28): 187-195.

Gundogan M., D. Yeni., F. Avdatek and A.F. Fidan, 2010. Influence of sperm concentration on the motility, morphology, and membrane and DNA integrity along with oxidative stress parameters of ram sperm during liquid storage. Anim. Reprod. Sci, (122): 200-207.

Hargreaves J.A., J.W. Mansfield and D.T. Coxon, 1976. Identification of medicarpin as a phytoalexin in the broad bean plant (Vicia faba L.). Nature, (262): 318-319.

Hashem E. Z., R. Haddad and M. Eslami, 2017. Evaluation of ram semen enrichment with oleic acid on different spermatozoa parameters during low temperature liquid storage. Small Rumin. Rese, (150): 30-39.

IBM Corp., 2013. IBM SPSS Statistics for Windows, Version 22.0. Armonk, NY: IBM Corp.

Jasprica D., A. Mornar., Z. Debelijak., A. SmolcicBubalo., M. Medic-Saric., L. Mayer., Z. Romic., K. Bucan., T. Balog., S. Sobocanec and V. Sverko, 2007. In vivo study of propolis supplementation effects on antioxidative status and red blood cells. J. Ethnopharmacology, (110): 548-554.

Jha P.K., A.K. Paul., M.B. Rahman., M. Tanjim., F.Y. Bari and M.G. Alam, 2013. Improvement of preservation quality of chilled bull semen using $\alpha$-tocopherol as an antioxidant. J. Embryo Transfer, (28): 31-39.

Korneev S.M., 2013. Hydrocinnamic Acids: Application and Strategy of Synthesis. Synthesis, (45): 1000-1015.

Kulaksiz R., C. Cebi and E. Akçay, 2012. The effect of different extenders on the motility and morphology of ram sperm frozen or stored at 4 ${ }^{\circ}$ C. Turk. J. Vet. Anim. Sci, (36): 177- 182.

Kumazawa S., T. Hamasaka and T. Nakayama, 2004. Antioxidant activity of propolis of various 
geographic origins. Food Chem, (84): 329-339.

Makker K., A. Agarwal and R. Sharma, 2009. Oxidative stress \& male infertility. Ind. J. Med. Res, (29) 357-367.

Martínez-Sotres C., P. López-Albarrán., J. Cruz-deLeón., T. García-Moreno., J. G. RutiagaQuiñones., G. VázquezMarrufo and H.B.R. Tamariz-Mascarúa, 2012. Medicarpin, an antifungal compound identified in hexane extract of Dalbergia congestiflora Pittier heartwood. Int Biodeter Biodegr, (69): 38-40.

Mathur P.P. and S.C. D'Cruz, 2011. The effect of environmental contaminants on testicular function. Asian J. Androl, (13): 585-591.

Morrell J.M., 2006. Update on semen technologies for animal breeding. Reprod. Dom. Anim, (41): 63-67.

Morrell J.M. and M. Wallgren, 2014. Alternatives to Antibiotics in Semen Extenders: A Review. Pathogens, (3): 934-946.

Morsy A.S., A.L. Abdalla., Y.A. Soltan., S.M. Sallam., K.M. El-Azrak., H. Louvandini and S.M. Alencar, 2013. Effect of Brazilian red propolis administration on hematological, biochemical variables and parasitic response of Santa Inês ewes during and after flushing period. Trop. Anim. Health Prod, (45): 1609-1618.

Morsy A.S., Y.A. Soltan., S.M. Sallam., M. Kreuzer., S.M. Alencar and A.L. Abdalla, 2015. Comparison of the in vitro efficiency of supplementary beepropolis extracts of different origin in enhancing the ruminaldegradability of organic matter and mitigating the formation of methane. Anim. Feed Sci. Technol, (199): 51-60.

Mosaferi S., N.A. Niasari., A. Abarghani., A.A. Gharahdaghi and A. Gerami, 2005. Biophysical and biochemical characteristics of Bactrian camel semen collected by artificial vagina. Theriogenology, (63): 92-101.

Munsi M.N., M.M.U. Bhuiyan., S. Majumder and M.G.S. Alam, 2007. Effects of exogenous glutathion on the quality of chilled bull semen. Reprod. Dom. Anim, (42): 358-362.

Nader M.A., D.S. El-Agamy and G.M. Suddek, 2010. Protective effects of propolis and thymoquinone on development of atherosclerosis in cholesterolfed rabbits. Arch. Pharm. Res, (33): 637-643.

NRC, National Research Council of the National Academies., 2007. Nutrient requirement of small ruminants: sheep, goats, cervids, and new world camelids. The National Academies press, 500 Fifth Street, NW, Washington DC, USA.

Paul C.M., S. Tang and P. Saunders, 2009. A single, mild, transient scrotal heat stress hypoxia and oxidative stress in mouse testes, which induces germ cell death. Biol. Reprod, (80): 913-919.

Paulino N., S. Abreu., Y. Uto., D. Koyama., H. Nagasawa., H. Hori., V. Dirsch., A. Vollmar., A. Scremin and W. Bretz, 2008. Anti-inflammatory effects of a bioavailable compound, Artepillin C, in Brazilian propolis. Europ. J. Pharmacol, (587): 296-301.

Pesch S., M. Bergmann and H. Bostedt, 2006. Determination of some enzymes and macro and microelements in stallion seminal plasma and their correlations to semen quality. Theriogenology, (66): 307-313.

Rateb S.A., 2006. Improving Artificial Insemination Efficiency in Doe Goats Using Oxytocin to Induce Cervical Dilation. M. Sc. Thesis, Faculty of Agriculture, Alexandria University, Egypt.

Salmon S. and W.M.C. Maxwell, 1995a. Frozen storage of ram semen. I. Processing, freezing, thawing and fertility after cervical insemination. Anim. Reprod. Sci, (37): 185- 249.

Salmon S. and W.M.C. Maxwell, 1995b. Frozen storage of ram semen. II. Causes of low fertility after cervical insemination and methods of improvement. Anim. Reprod. Sci, (38): 1- 55.

Scalbert A., I.T. Johnson and M. Saltmarsh, 2005. Polyphenols antioxidants and beyond. American J. Clin. Nutr, (81): 215-217.

Scazzocchio F., F.D. D'Auria., D. Alessandrini and F. Pantanella, 2006. Multifactorial aspects of antimicrobial activity of propolis. Microbiol. Res, (161): 327-333.

Shukla M.K., 2005. Correlation of microbial load of cryopreserved semen with quality of neat and cryopreserved murrah buffalo bull semen. Buffalo Bulletin, (24): 84-87.

Simoes L., L. Gregório., A. da Silva Filho., M. de Souza., A. Azzolini., J. Bastos and Y. LucisanoValim, 2004. Effect of Brazilian green propolis on the production of reactive oxygen species by stimulated neutrophils. J. Ethnopharmacology, (94): 59-65.

Yousef M. and A. Salama, 2009. Propolis protection from reproductive toxicity caused by aluminium chloride in male rats. Food Chem. Toxicol, (47): 1168-1175. 


\section{تاثير تلاعيم بيئة حفظ الحيوانات المنوية بمستخلص البروبليس البرازيلي الاحمر من النوع rا I علي المقدرة الحفظية

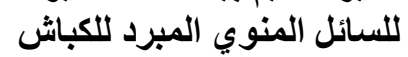

ابراهيم سمير عبد الحميد'، مروة احمد خليفة'، شريف عبد الرزاق راتب'، عمرو صلاح مرسي'، محمد طارق بدوي'، حمدي عبد العزيز جاويش'

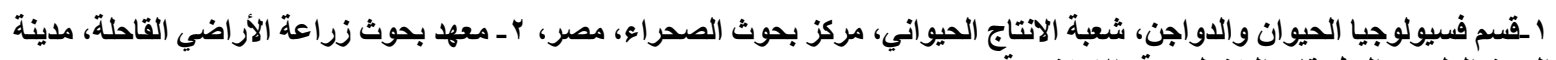

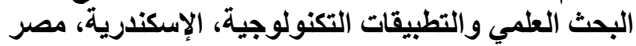

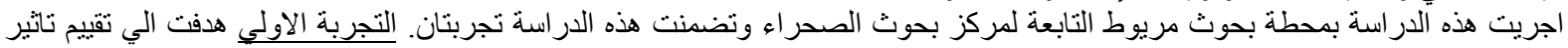

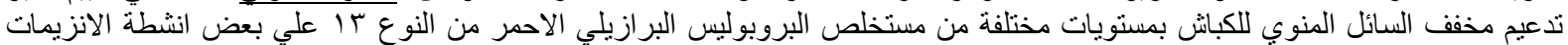

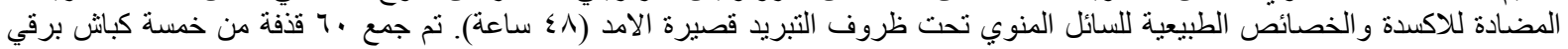

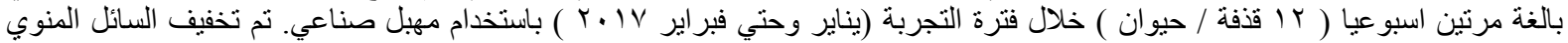

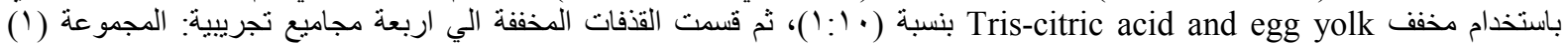

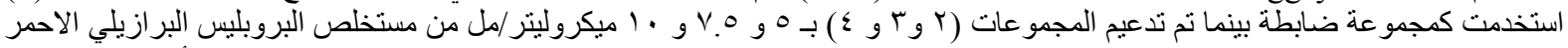

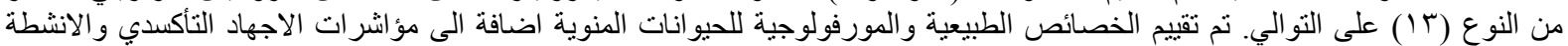

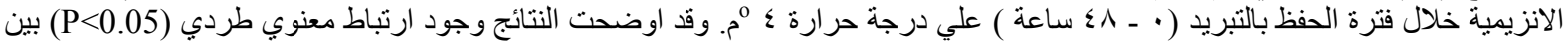

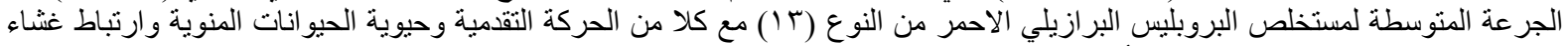

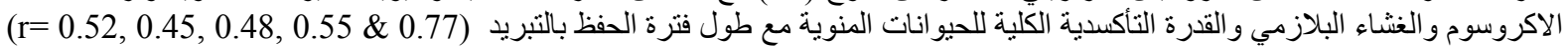

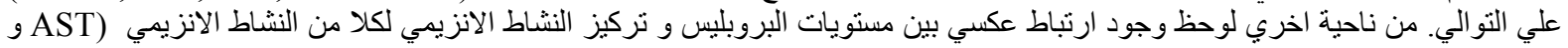

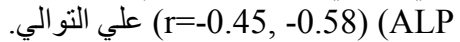

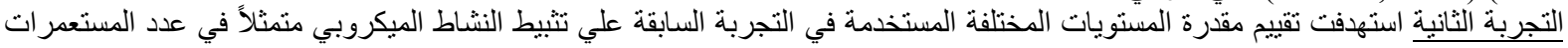

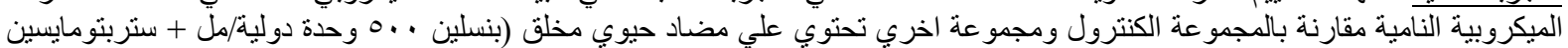

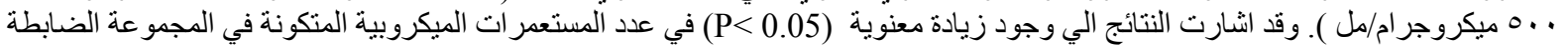

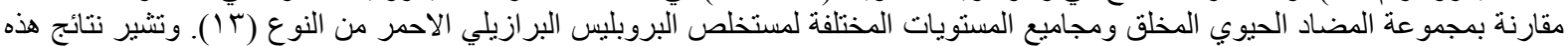

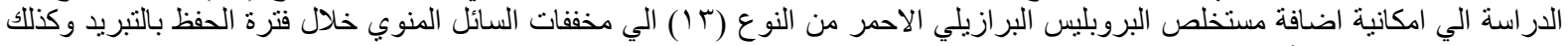

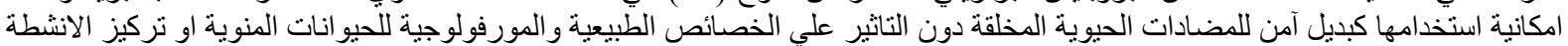

